\title{
Alternative models for analyses of liver and mammary transorgan metabolite extraction data
}

\author{
M. D. Hanigan ${ }^{1 *}$, J. France $^{2} \dagger$, D. Wray-Cahen ${ }^{3} \ddagger$, D. E. Beever ${ }^{3}$, G. E. Lobley ${ }^{4}$, \\ L. Reutzel ${ }^{1}$ and N. E. Smith ${ }^{1}$ \\ ${ }^{1}$ Purina Mills, Inc., St Louis, MO 63144, USA \\ ${ }^{2}$ Institute of Grasslands and Environmental Research, North Wyke Research Station, Okehampton EX2 OSB, UK \\ ${ }^{3}$ University of Reading, Whiteknights, Reading RG6 6AH, UK \\ ${ }^{4}$ Rowett Research Institute, Bucksburn, Aberdeen AB21 9SB, UK
}

(Received 27 November 1996 - Revised 12 June 1997 - Accepted 14 July 1997)

\begin{abstract}
Alternative models for analyses of liver and mammary transorgan data were formulated and fitted to liver and mammary data sets respectively. The models considered metabolite inputs to and effluxes from an extracellular pool. In general, fits were greatly improved over previous efforts using other models (Miller et al. 1991a; Hanigan et al. 1992; Wray-Cahen et al. 1997). Errors of prediction were generaliy less than $15 \%$ for liver and less than $20 \%$ for mammary glands. With the possible exception of glutamine for the udder, all metabolites exhibited linear responses to extracellular concentrations within the observed ranges of inputs. However, prediction biases were evident for $\beta$-hydroxybutyrate, acetate, and propionate by liver and for arginine, histidine, citrulline and glycerol by mammary tissue. These biases were hypothesized to be caused by the existence of additional regulatory complexity. With the exception of histidine, parameter estimates for essential amino acid removal by liver were 2 -3-fold lower than for mammary gland. Infusion of an amino acid mixture into the mesenteric vein did not alter parameter estimates for removal of amino acids by the liver. Treatment of cows with bovine somatotropin resulted in changes in mammary parameter estimates for aspartate, glutamate, leucine, phenylalanine, glucose, and glycerol.
\end{abstract}

Mathematical modelling: Liver: Mammary gland

Attempts to define relationships among metabolite inputs to and uptake by an organ (both $\mathrm{mol} / \mathrm{d}$ ) have resulted in prediction equations with limited precision (Hanigan \& Baldwin, 1995; Wray-Cahen et al. 1997). Exclusion of blood flow from such consideration, i.e. regression of arteriovenous differences $v$. arterial concentrations (both $\mathrm{mol} /$ 1), has resulted in prediction equations with only marginally greater levels of precision (Miller et al. 1991a; Hanigan et al. 1992; Cant et al. 1993). However, both of these approaches have failed to consider the effects of blood flow changes on metabolite efflux from the extracellular space. Such an omission may be the primary reason for the lack of fit observed when these equations were applied to a variety of metabolites.

In order to utilize more accurately, and thereby interpret information derived from, arteriovenous difference studies, it is hypothesized that a model that accommodates arterial metabolite concentration and organ blood flow as inputs and extracellular concentration and organ blood flow as outputs must be utilized. In the case of the liver, additional inputs from the portal vein must be considered. The objective of the present study, therefore, was to devise and test models of liver and mammary organ extraction that consider the effects of blood entry and exit from the system.

\section{Materials and methods \\ Model description}

Taking the more complex situation associated with liver, the simple model depicted in Fig. 1 can be proposed where $C_{A}$ and $C_{P}$ refer to arterial and portal metabolite 


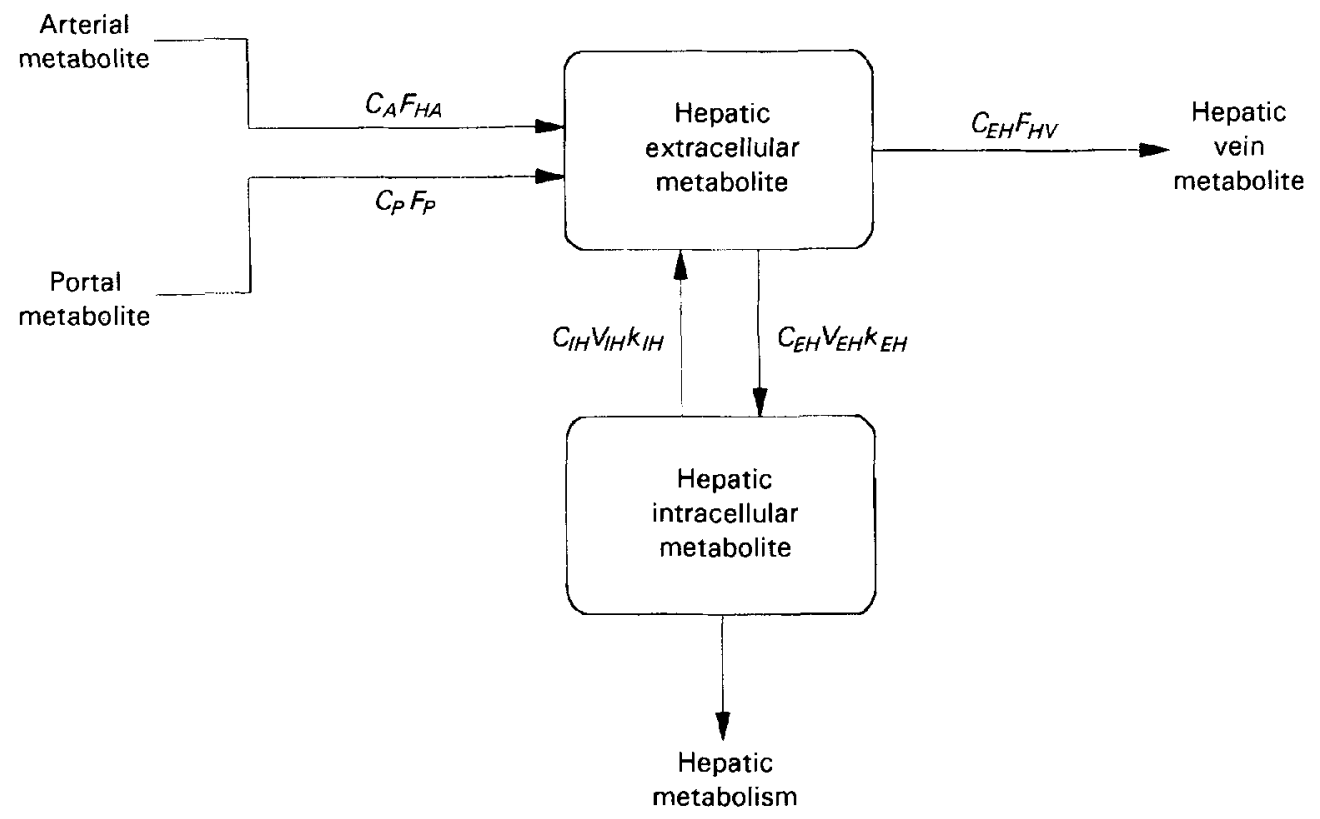

Fig. 1. Block diagram depicting a transorgan extraction model for liver. $C_{A}$, arterial metabolite concentration; $C_{P}$, portal metabolite concentration; $F_{H A}$, arterial blood flow; $F_{P}$, portal blood flow; $F_{H V}$, hepatic-vein blood flow; $k_{E H}, k_{H H}$, rate constants for hepatic extracellular and intracellular metabolite pools; $C_{E H}, C_{I H}$, metabolite concentrations in heptatic extracellular and intracellular pools; $V_{E H}, V_{I H}$, volumes of hepatic extracellular and intracellular metabolite pools.

concentrations (mol/1), respectively; $F_{H A}, F_{P}$, and $F_{H V}$ refer to arterial, portal-vein, and hepatic-vein blood flows (litres/ d) respectively; and $k_{E H}, k_{I H}(/ \mathrm{d}), C_{E H}, C_{I H}(\mathrm{~mol} / \mathrm{l}), V_{E H}$ and $V_{I H}$ (litres) represent the rate constants, metabolite concentrations, and volumes for the hepatic extracellular and intracellular metabolite pools respectively. Hepaticvein flows are the sum of arterial and portal flows. Flows and concentrations can represent either plasma or wholeblood values.

The proposed model can only be tenable if one makes several assumptions relative to the physical system. These are: (1) the capillary and tissue interstitial pools can be treated as a common (extracellular) pool. In order to assume such, capillary and interstitial metabolites must exchange very rapidly and freely (Detweiler, 1984; Risau, 1995). Such an assumption may not be true for larger molecules such as albumin (Matsumoto et al. 1994); (2) forward and reverse metabolite transport across the cell membrane is linear with respect to concentrations. Although it has been demonstrated that the majority of amino acid transporters exhibit saturation kinetics, concentrations required to saturate the active transport process were generally found to be much greater than the observed range for in vivo concentrations (Oxender \& Christensen, 1963; Christensen et al. 1967; Bass et al. 1981). Transporters for other metabolites apparently have not been characterized adequately enough to evaluate the adequacy of this assumption; (3) extracellular and intracellular metabolite concentrations are proportional (Clark et al. 1980).

Obviously, these assumptions do not encompass all the intricacies of liver perfusion and metabolism. However, such a model and the associated assumptions can serve as a starting point, wherein more complexity can be added as required. Using the principle of conservation of mass, the differential equation describing the extracellular metabolite pool is:

$$
\begin{aligned}
\frac{\mathrm{d}\left(C_{E H} V_{E H}\right)}{\mathrm{d} t}= & C_{A} F_{H A}+C_{P} F_{P}+k_{I H} C_{I H} V_{I H} \\
& -k_{E H} C_{E H} V_{E H}-C_{E H} F_{H V} .
\end{aligned}
$$

Based on assumption 1 and as depicted in Fig. 1, extracellular and hepatic-vein concentrations of metabolite are equal:

$$
C_{E H}=C_{H V}
$$

Following from assumption 3, intracellular and hepaticvein concentrations are linearly related:

$$
C_{I H}=\beta C_{E H}=\beta C_{H V},
$$

where $\beta$ is a proportionality constant. Substituting for $C_{E H}$ and $C_{I H}$ in the right hand side of equation 1 gives:

$$
\begin{aligned}
\frac{\mathrm{d}\left(C_{E H} V_{E H}\right)}{\mathrm{d} t}= & C_{A} F_{H A}+C_{P} F_{P} \\
& +C_{H V}\left(k_{I H} \beta V_{I H}-k_{E H} V_{E H}-F_{H V}\right) .
\end{aligned}
$$

Given that flows of blood through the extracellular space of the liver are relatively large as compared with the volume of extracellular space (for cows, flow is $20-40$ litres/min $v$. an extracellular space of 2-3 litres; Waghorn, 1982; Reynolds et al. 1988; Wray-Cahen et al. 1997), one can assume that the system is in steady state except for time frames of less than a few minutes, i.e. changes in extracellular volume or in input concentrations or flows 
will result in a new steady state in a very short time. Therefore, in most cases $\mathrm{d}\left(C_{E H} V_{E H}\right) / \mathrm{d} t$ is zero:

$$
C_{A} F_{H A}+C_{P} F_{P}+C_{H V}\left(k_{I H} \beta V_{I H}-k_{E H} V_{E H}-F_{H V}\right)=0 .
$$

If one assumes that uptake of a given metabolite by the tissue will always either be positive (removal) or negative (release) with no crossover as inputs range from low to high (the sign of uptake does not change through this range) and that the extracellular and intracellular volumes remain constant over the observation period, then one can let $K_{H}=k_{E H} V_{E H}-k_{I H} \beta V_{I H}$ in equation 5 where $K_{H}$ represents a parameter derived from the true rate constants for transport of the metabolite across the cell membrane and intracellular and extracellular volumes and has units of litres/d. Therefore, a change in $K_{H}$ can occur if either the rate constants or the volumes change. In the case of triacylglycerol (TAG), apparent removal is catalysed by lipoprotein lipase $(E C$ 3.1.1.34) at the endothelial cell surface rather than after transport into the cell. Given that the lipase reaction is largely irreversible, a unidirectional representation is actually more appropriate. Rearranging equation 5 gives:

$$
C_{H V}=\frac{C_{A} F_{H A}+C_{P} F_{P}}{K_{H}+F_{H V}} .
$$

Therefore, using equation 6 , hepatic-vein concentrations can be predicted from arterial and portal blood flows and concentrations if the parameter $K_{H}$ is known. Conversely, using measured arterial, portal, and hepatic-vein concentrations and blood flows as inputs, $K_{H}$ can be determined.

A similar model can be proposed for udder as depicted in Fig. 2. $C_{A}$ and $C_{E M}$ refer to arterial and mammary extracellular metabolite concentrations (mol//) respectively, and $F_{M}$ refers to mammary blood flow (litres/d).
$k_{E M}, k_{I M}($ both $/ \mathrm{d}), C_{E M}, C_{I M}($ both $\mathrm{mol} / \mathrm{/}), V_{E M}$, and $V_{I M}$ (both litres) represent the rate constants, metabolite concentrations, and volumes for the mammary extracellular and intracellular metabolite pools respectively.

The differential equation for the extracellular pool of this model is:

$$
\begin{aligned}
\frac{\mathrm{d}\left(C_{E M} V_{E M}\right)}{\mathrm{d} t}= & C_{A} F_{M}+k_{I M} C_{I M} V_{I M} \\
& -k_{E M} C_{E M} V_{E M}-C_{E M} F_{M} .
\end{aligned}
$$

Using the same assumptions as for liver:

$$
C_{E M}=C_{M V},
$$

and the mammary intracellular and extracellular concentration are linearly related, i.e.

$$
C_{I M}=\gamma C_{E M}=\gamma C_{M V},
$$

where $\gamma$ is a proportionality constant. Substituting for $C_{E M}$ and $C_{I M}$ in the right hand side of equation 7 gives:

$$
\frac{\mathrm{d}\left(C_{E M} V_{E M}\right)}{\mathrm{d} t}=C_{A} F_{M}-C_{M V}\left(k_{I M} \gamma V_{I M}-k_{E M} V_{E M}-F_{M}\right)
$$

As for liver, flow of blood through the extracellular space of the mammary gland is relatively large as compared with the volume of extracellular space (for cows, flows are 6-12 litres/min $v$. an extracellular space of 4-5 litres; Waghorn \& Baldwin, 1984; Hanigan \& Baldwin, 1995). Thus one can assume that the system is in steady state over time frames of greater than a few minutes. Therefore, in most cases $\mathrm{d}\left(C_{E M} V_{E M}\right) / \mathrm{d} t$ is zero:

$$
C_{A} F_{M}+C_{M V}\left(k_{I M} \gamma V_{I M}-k_{E M} V_{E M}-F_{M}\right)=0 .
$$

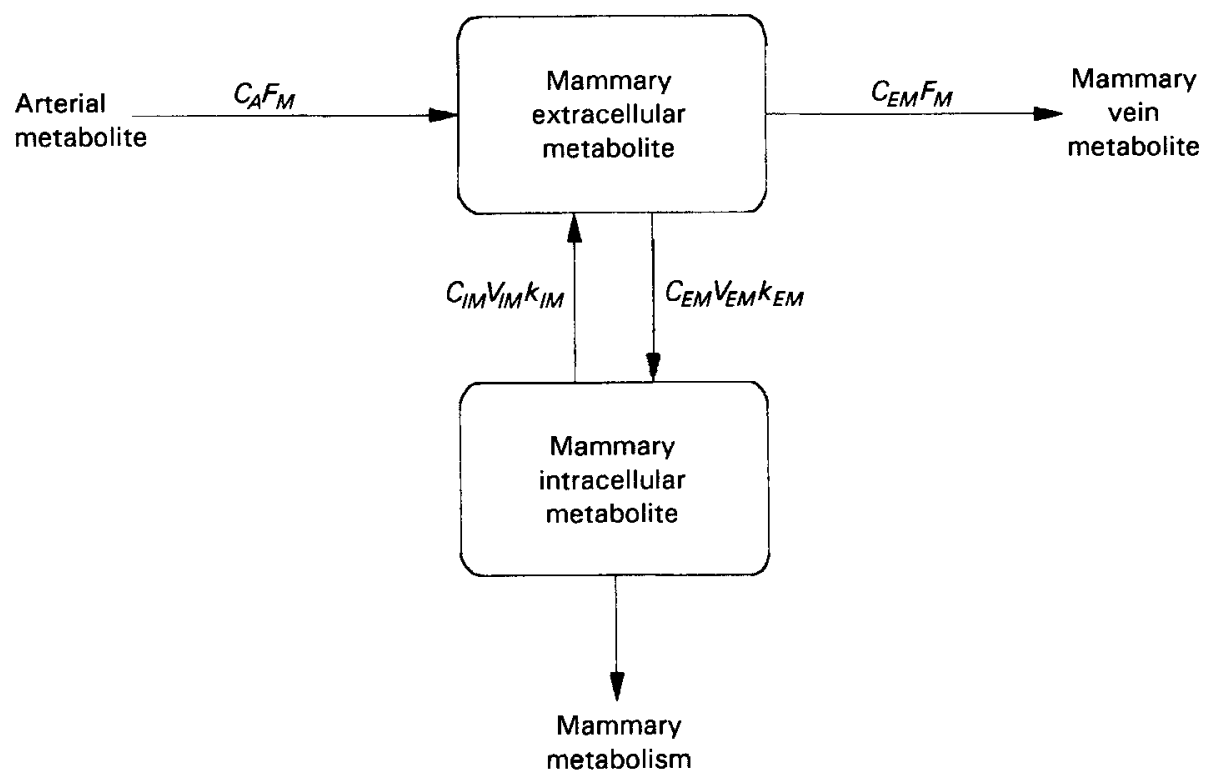

Fig. 2. Block diagram depicting a transorgan extraction model for mammary gland. $C_{A}$, arterial metabolite concentration; $C_{E M}$, mammary extracellular metabolite concentration; $F_{M}$, mammary blood flow; $k_{E M}, k_{M M}$, rate constants for mammary extracellular and intracellular metabolite pools; $C_{E M}, C_{I M}$, metabolite concentrations in mammary extracellular and intracellular pools; $V_{E M}, V_{M}$, volumes of mammary extracellular and intracellular metabolite pools. 
Using the same assumptions as for liver regarding the sign of uptake, one can let $K_{M}=k_{E M} V_{E M}-k_{I M} \gamma V_{I M}$ in equation 11 and rearrange to give:

$$
C_{M V}=\frac{C_{A} F_{M}}{K_{M}+F_{M}} .
$$

Therefore, using equation 12 , mammary-vein concentrations can be predicted from arterial flows and concentrations if the parameter $K_{M}$ is known, or $K_{M}$ can be determined from measured arterial and mammary venous concentrations and blood flow.

\section{Data fitting}

Data used to apply the liver model were from non-lactating cows as described by Wray-Cahen et al. (1997). Data used to apply the mammary model were from lactating cows as described by Miller et al. (1991a,b), Hanigan et al. (1991, 1992) and Hanigan \& Baldwin (1995).

The non-linear (NLIN) procedure of Statistical Analysis Systems (1988) was used to derive rate constant estimates from equations 6 and 12. The search method used was DUD (does not use derivatives) (Statistical Analysis Systems, 1988). This routine iteratively searches for the minimal residual sums of squares $(S S R)$ while varying $K_{M}$ or $K_{H}$. The parameter value coinciding with the minimum SSR is the best estimate for the data set under study. An asymptotic $95 \% \mathrm{CI}$ for the parameter estimate was calculated from residual errors (Statistical Analysis Systems, 1988), and CV for predictions of venous concentrations were calculated from $S S R$ and the observed mean venous concentration $\left(C_{\text {Mean }}\right)$ :

$$
C V=\sqrt{\frac{S S R / D F_{\text {Residual }}}{C_{\text {Mean }}}} \times 100,
$$

where $D F_{\text {Residual }}$ was the residual degrees of freedom. The percentage of venous concentration variation explained by the model was calculated as:

$$
\operatorname{explained}(\%)=\left[1-\frac{S S R}{\sum\left(C_{i}-C_{\text {Mean }}\right)^{2}}\right] \times 100,
$$

where $C_{i}$ represented individual observed venous concentrations.

As the models described herein contained a single parameter $(K)$, the only valid $F$-statistic that could be constructed would utilize the uncorrected total sums of squares $\left(\mathrm{SST}_{\mathrm{U}}\right)$, i.e. comparison with the mean venous value (also one parameter fitted) results in a divisor of 0 in the numerator of the $F$-statistic thereby preventing use of the mean venous value in the calculation. However, the magnitude of the $\mathrm{SST}_{\mathrm{U}}$ is dictated by the magnitude of the values considered where larger values result in a larger $\mathrm{SST}_{\mathrm{U}}$. Consequently, even a poorly constructed model could result in a large $F$-statistic if the dependent variable was of great magnitude. Therefore, rejection of these models as adequate descriptors of the data was based on the results generated from equation 14 rather than on an $F$-statistic.
When plasma amino acid data were considered, plasma concentrations were used for arterial, portal, hepatic-vein, and mammary-vein parameters and whole-blood flows were used for each of those vessels. Such an approach assumes that delivery contributions of erythrocytes were equivalent to plasma when adjusted for volume differences. This assumption has been shown to be false for some amino acids (Heitmann \& Bergman, 1980; Hanigan et al. 1991) and, thus, was examined as part of the evaluation. A similar assumption was made for all other metabolites that were measured in plasma with the exception of glucose and $\mathrm{CO}_{2}$ which were assumed to be transported only in plasma (Roughton, 1964; Huntington, 1984). Data adequate to examine this assumption are not currently available.

Where treatment effects were examined, the models (equations 6 and 12) were fitted to the data set as a whole and separately to each treatment group. An $F$-statistic was calculated from residuals and used to determine probability values for differences in $K_{H}$ or $K_{M}$ estimates among treatment groups:

$$
F=\frac{\left(S S R_{\text {Total }}-\sum S S R_{T r}\right) /\left(N_{T r t}-1\right)}{\sum S S R_{T r t} /\left(N_{\text {Total }}-N_{T r t}\right)},
$$

where $S S R_{\text {Total }}$ and $S S R_{T r}$ represented the residual sum of squares when the models were fitted to the entire data set and to individual treatment groups respectively. $N_{\text {Total }}$ and $N_{T r r}$ represented the total number of observations and the number of treatments respectively.

\section{Results}

Results of liver analyses are presented in Table 1. Examination of equation 6 reveals that negative estimates for $K_{H}$ denote output by the liver and positive estimates uptake. Metabolites exhibiting positive estimates for $K_{H}$ include: alanine, arginine, asparagine, glutamine, glycine, histidine, lysine, methionine, phenylalanine, proline, serine, threonine, tyrosine, $\mathrm{O}_{2}$, propionate, $\mathrm{N}$-butyrate, lactate, and $\mathrm{NH}_{3}$. Estimates of $K_{H}$ for aspartate, isoleucine, leucine, and valine were not significantly different from 0 indicating that net removal was not significantly different from 0 . Estimates of $K_{H}$ for glutamate, glucose, acetate, $\beta$ hydroxybutyrate, and urea were negative indicating release of those metabolites. The model fitted glutamate, glucose, $\beta$-hydroxybutyrate, and urea data with high accuracy indicating that there was a strong correlation among systemic concentrations and hepatic production of those metabolites.

Results from mammary analyses are presented in Table 2. With the exception of histidine, parameter estimates for all metabolites were positive; however, $K_{M}$ for cystine, glycine, histidine, lactate, and urea were not significantly different from 0 . The $K_{H}$ for insulin-like growth factor-1 (IGF-1) was negative but non-significant.

Separate estimates of $K_{H}$ were made for whole blood and plasma and are presented in Table 3 . Estimates were significantly different for asparagine, histidine, isoleucine, leucine, lysine, methionine, phenylalanine, serine, threonine, and tyrosine. A similar analysis was not performed for liver as the analyses of whole blood and plasma data were 
Table 1. Parameter estimates for metabolite uptake by liver from extracellular space*

\begin{tabular}{|c|c|c|c|c|c|c|}
\hline & \multirow[b]{2}{*}{$K_{H}($ litres/d) } & \multicolumn{2}{|c|}{$\begin{array}{l}95 \% \text { Confidence interval } \\
\text { (litres/d) }\end{array}$} & \multirow{2}{*}{$\begin{array}{l}\text { Predicted } \\
C_{H V}(\mu \mathrm{M})\end{array}$} & \multirow[b]{2}{*}{$\begin{array}{l}\mathrm{CV} \text { of the } \\
\text { prediction }\end{array}$} & \multirow[b]{2}{*}{$\begin{array}{c}\text { Variation } \\
\text { explained }(\%)\end{array}$} \\
\hline & & Lower & Upper & & & \\
\hline \multicolumn{7}{|l|}{ Amino acids } \\
\hline Alanine & 4650 & 4008 & 5293 & 322 & 8.29 & 99.0 \\
\hline Arginine & 3776 & 2965 & 4588 & 85.8 & 10.73 & 98.8 \\
\hline Asparagine & 4054 & 1817 & 6290 & 27.2 & 17.72 & 41.6 \\
\hline Aspartate & 114 & -2181 & 2409 & 19.1 & 20.75 & 37.4 \\
\hline Glutamine & 4656 & 3513 & 5798 & 164 & 11.92 & 90.2 \\
\hline Glutamate & -5956 & -6916 & -4996 & 181 & 13.42 & $83 . \overline{5}$ \\
\hline Glycine & 4537 & 3751 & 5322 & 326 & 9.47 & 98.2 \\
\hline Histidine & 2165 & 1581 & 2748 & $98 \cdot 3$ & 7.61 & 98.9 \\
\hline Isoleucine & 247 & -370 & 865 & 163 & 7.93 & 97.8 \\
\hline Leucine & 215 & -280 & 710 & 184 & 6.38 & 98.6 \\
\hline Lysine & 855 & 219 & 1491 & 127 & 8.02 & 97.9 \\
\hline Methionine & 4280 & 3271 & 5286 & 42.8 & $14 \cdot 23$ & 97.9 \\
\hline Phenylalanine & 4971 & 4093 & 5849 & 69.3 & 9.7 & 96.8 \\
\hline Proline & 3225 & 1906 & 4544 & 110 & 17.87 & 96.7 \\
\hline Serine & 4772 & 3557 & 5987 & 104 & 10.93 & 96.2 \\
\hline Threonine & 1514 & 717 & 2312 & 119 & 8.29 & 98.1 \\
\hline Tyrosine & 2280 & 1555 & 3005 & 46.9 & 7.67 & 87.4 \\
\hline Valine & -166 & -1715 & 1383 & 232 & $20 \cdot 15$ & 88.7 \\
\hline \multicolumn{7}{|l|}{ Other metabolites } \\
\hline $\mathrm{O}_{2}$ & 27408 & 23441 & 31376 & 2270 & $19 \cdot 26$ & 37.8 \\
\hline Glucose & -3178 & -3454 & -2902 & 2770 & 2.63 & 84.9 \\
\hline Acetate & -2302 & -3423 & -1182 & 2700 & 10.02 & 31.5 \\
\hline Propionate & 141047 & 121716 & 160378 & 0.0885 & 33.71 & 1.3 \\
\hline Butyrate (N) & 40318 & 35108 & 45527 & 0.0629 & 24.77 & 9.9 \\
\hline BHBA & -4989 & -5679 & -4300 & 933 & 7.46 & 87.7 \\
\hline Lactate & 8313 & 5993 & 10633 & 349 & 17.84 & 86.5 \\
\hline Urea & -5411 & -5909 & -5014 & 2430 & $4 \cdot 21$ & 94.0 \\
\hline $\mathrm{NH}_{3}$ & 132561 & 113032 & 152091 & 95.1 & 35.32 & 23.2 \\
\hline
\end{tabular}

BHBA, $\beta$-hydroxybutyrate; $K_{H}$, rate constant; $C_{H V}$, hepatic-vein metabolite concentrations.

- Data used were from non-lactating dairy cows, and were fitted to equation 6 (p. 65).

conducted on different analysers and therefore cannot be directly compared.

The treatment effects of bovine somatotropin (bST) on estimates were also examined for the mammary data and are presented in Table 4. For this analysis, only wholeblood observations were used. Treatment with bST resulted in a significant increase in $K_{M}$ for aspartate and leucine and a significant decrease in $K_{M}$ for glutamate, phenylalanine, glucose, and glycerol.

Example plots of several amino acids and selected energy substrates are presented for liver (Fig. 3) and mammary gland (Fig. 4). For the majority of metabolites, removal by liver and mammary gland did not deviate from linearity with respect to extracellular concentrations. However, glutamine removal by mammary gland appeared to be enhanced at the upper end of the observed concentration range (Fig. 4), resulting in observed $C_{M V}$ values that were less than predicted $C_{M V}$. Residual errors for predictions of hepatic venous concentrations of $\beta$ hydroxybutyrate, acetate, and propionate (Fig. 5) and mammary venous concentrations of arginine, histidine, citrulline, and glycerol (Fig. 6) exhibited linear biases with respect to predicted extracellular concentrations as compared with the more normal distribution of errors associated with $\mathrm{O}_{2}$ predictions (Fig. 5). However, these biases were restricted to predictions of whole-blood concentrations for histidine and citrulline. For each of these metabolites, venous concentrations were underpredicted at low predicted venous concentrations and overpredicted at greater predicted venous concentrations suggesting that other factors were involved in regulating removal of these metabolites by the respective tissues.

\section{Discussion}

Previous efforts to describe relationships among inputs and uptakes of metabolites by mammary gland and liver did not consider the effects of blood flow on metabolite exit from the tissue and generally explained from 20 to $40 \%$ of the observed variance for mammary gland (Miller et al. 1991a; Hanigan et al. 1992) and a similar amount for liver (results not shown). Consequently, the present models appeared to fit mammary and liver data better, generally explaining greater than $80 \%$ of the observed variance for liver and $60 \%$ of the observed variance for mammary gland. The lack of prediction bias for the majority of the metabolites suggests that extractions were linear within the observed range of concentrations and, thereby, that both the liver and mammary gland apparently have excess capacity for extraction of these metabolites. Even when amino acid concentrations were more than doubled by systemic infusion of exogenous amino acids (Wray-Cahen et al. 1997), hepatic extractions did not appear to deviate from 
Table 2. Parameter estimates for metabolite uptake by mammary gland from extracellular space*

\begin{tabular}{|c|c|c|c|c|c|c|}
\hline & \multirow[b]{2}{*}{$K_{M}($ litres/d) } & \multicolumn{2}{|c|}{$\begin{array}{l}95 \% \text { Confidence interval } \\
\text { (litres/d) }\end{array}$} & \multirow{2}{*}{$\begin{array}{l}\text { Predicted } \\
C_{M V}(\mu \mathrm{M})\end{array}$} & \multirow{2}{*}{$\begin{array}{l}\text { CV of the } \\
\text { estimate }\end{array}$} & \multirow{2}{*}{$\begin{array}{c}\text { Variation } \\
\text { explained (\%) }\end{array}$} \\
\hline & & Lower & Upper & & & \\
\hline \multicolumn{7}{|l|}{ Amino acids } \\
\hline Alanine & 2336 & 1902 & 2770 & 187 & 11.07 & 86.9 \\
\hline Arginine & 17806 & 16102 & 19511 & 41.5 & 23.37 & $25 \cdot 6$ \\
\hline Asparagine & 6128 & 5429 & 6828 & 37.9 & 14.75 & 78.4 \\
\hline Aspartate & 651 & 144 & 1157 & 61.6 & 19.29 & 97.0 \\
\hline Cystine & 873 & -158 & 1904 & 35.6 & 27.62 & 39.9 \\
\hline Giutamine & 6591 & 4835 & 8347 & 78.5 & 39.62 & 70.4 \\
\hline Glutamate & 6430 & 5416 & 7445 & 108 & 20.79 & $56 \cdot 1$ \\
\hline Glycine & 263 & -246 & 772 & 356 & 14.01 & 79.5 \\
\hline Histidine & -1468 & -3012 & 76 & 74.0 & 46.66 & 1.8 \\
\hline Isoleucine & 14405 & 13112 & 15697 & $88 \cdot 6$ & 20.03 & 76.8 \\
\hline Leucine & 5917 & 5084 & 6750 & 127 & $17 \cdot 50$ & 69.7 \\
\hline Lysine & 11706 & 10408 & 13005 & 54.6 & 22.97 & 83.4 \\
\hline Methionine & 16113 & 14064 & 18162 & 10.5 & 29.70 & $43 \cdot 3$ \\
\hline Phenylalanine & 7654 & 6795 & 8514 & $37 \cdot 3$ & $16 \cdot 64$ & 52.8 \\
\hline Proline & 1304 & 892 & 1717 & 103 & 11.11 & 85.7 \\
\hline Serine & 6492 & 5588 & 7395 & 67.4 & $18 \cdot 27$ & 74.7 \\
\hline Threonine & 5711 & 5108 & 6313 & 68.9 & 12.97 & 84.3 \\
\hline Tryptophan & 2174 & 1387 & 2961 & $14 \cdot 2$ & 20.83 & 82.9 \\
\hline Tyrosine & 7059 & 6285 & 7833 & 41.0 & $16 \cdot 22$ & 83.5 \\
\hline Valine & 3383 & 2960 & 3806 & 276 & 9.94 & 86.4 \\
\hline \multicolumn{7}{|l|}{ Other metabolites } \\
\hline Glucose & 3490 & 2764 & 4216 & 2750 & $5 \cdot 75$ & 38.4 \\
\hline Acetate & 27570 & 24546 & 30593 & 891 & 23.59 & 29.1 \\
\hline NEFA & 2923 & 2115 & 3730 & 280 & 14.45 & 94.3 \\
\hline TAG & 12562 & 10521 & 14603 & $60.7 \dagger$ & 24.76 & 64.5 \\
\hline Glycerol & 4723 & 2092 & 7353 & 34.8 & 39.26 & 34.6 \\
\hline BHBA & 14592 & 11542 & 17642 & 865 & 30.76 & 68.7 \\
\hline Lactate & 51 & -1577 & 1680 & 774 & 40.93 & 66.3 \\
\hline Urea & 142 & -330 & 614 & 2710 & 9.07 & 80.1 \\
\hline Citrulline & 1716 & 584 & 2847 & $49 \cdot 6$ & 28.69 & 73.9 \\
\hline Ornithine & 7101 & 6320 & 7883 & 54.8 & $16 \cdot 17$ & $86 \cdot 2$ \\
\hline IGF-1 & -707 & -4030 & 2617 & $28.5 \ddagger$ & 77.94 & 50.8 \\
\hline
\end{tabular}

NEFA, non-esterified fatty acids; TAG, triacylglycerol; BHBA, $\beta$-hydroxybutyrate; IGF-1, insulin-like growth factor-1; $K_{M}$, rate constant; $C_{M}$, mammary vein metabolite concentration.

- Data used were from lactating cows, and were fitted to equation 12 (p. 66).

$\dagger \mathrm{mg} / \mathrm{l}$.

$\ddagger \mu g / l$.

linearity. The general linearity of these responses (Figs. 3 and 4) was supportive of assumptions 1-3 made in the model description section (pp. 63-66). Given the observed linearity of these responses to concentration, one must conclude that both organs would respond to increased metabolite inputs by increasing metabolite removal. However, nothing can be inferred relative to the intracellular use of those metabolites. Even the observed biases (Figs. 5 and 6) are not consistent with a lack of capacity for removal, but rather, suggest alternative regulatory components.

Although the models used herein and the associated parameter estimates adequately describe these data, it cannot be determined from these analyses whether these parameter estimates can be applied universally. For example, it would be of interest to determine whether rate parameters for amino acid removal by liver change as the animal makes the transition from gestating to lactating states. Similarly, it would be of interest to determine whether the mammary rate parameters for all metabolites decline as lactation progresses, thereby coinciding with the observed decline in milk yield, or if they remain constant, thereby suggesting that other factors cause the observed decline. It would seem that these questions can be addressed through application of these models to appropriate experimental data. Before such an exercise, it would seem premature to suggest that these estimates can be universally applied.

Predictions can be loosely grouped according to their accuracy and the type of error exhibited. Those criteria have been used to structure much of the following discussion.

\section{Biased predictions}

As noted earlier, residual errors for predictions of venous concentrations exhibited linear bias for several metabolites. In general, these biases may indicate additional regulatory components associated with removal of the metabolite in question. Although the analysis itself cannot determine the cause of the bias, it can be useful in unravelling the problem. 
Table 3. Estimates of $K_{M}$ (litres/d) for amino acid uptake by the mammary gland from extracellular space, using inputs calculated from whole-blood observations (whole blood) or plasma concentrations and whole-blood flows (plasma)*

(Values are estimates with their standard errors)

\begin{tabular}{|c|c|c|c|c|c|}
\hline \multirow[b]{2}{*}{ Amino acid } & \multicolumn{2}{|c|}{ Whole blood } & \multicolumn{2}{|c|}{ Plasma } & \multirow[b]{2}{*}{$P<$} \\
\hline & $K_{M}$ & SE & $K_{M}$ & SE & \\
\hline Alanine & 2044 & 261 & 2923 & 388 & 0.06 \\
\hline Arginine & 16907 & 1088 & 18686 & 1348 & 0.31 \\
\hline Asparagine & 5374 & 431 & 8209 & 592 & 0.0005 \\
\hline Aspartate & 599 & 344 & 5989 & 851 & 0.06 \\
\hline Cystine & 1384 & 867 & -100 & 417 & 0.17 \\
\hline Glutamine & 6712 & 1264 & 4817 & 762 & 0.60 \\
\hline Glutamate & 5488 & 781 & 7142 & 653 & 0.11 \\
\hline Glycine & 365 & 309 & 18 & 465 & 0.54 \\
\hline Histidine & 2026 & 286 & -6104 & 390 & 0.0001 \\
\hline Isoleucine & 17010 & 603 & 6815 & 694 & 0.0001 \\
\hline Leucine & 3545 & 259 & 10526 & 794 & 0.0001 \\
\hline Lysine & 9051 & 410 & 26111 & 1953 & 0.0001 \\
\hline Methionine & 12703 & 1021 & 25203 & 2151 & 0.0001 \\
\hline Phenylalanine & 6075 & 396 & 10643 & 849 & 0.0001 \\
\hline Proline & 1188 & 268 & 1612 & 353 & 0.37 \\
\hline Serine & 5472 & 443 & 9031 & 1009 & 0.0005 \\
\hline Threonine & 4603 & 285 & 8544 & 588 & 0.0001 \\
\hline Tryptophan & 1926 & 512 & 3144 & 724 & 0.22 \\
\hline Tyrosine & 5680 & 283 & 11839 & 1013 & 0.0001 \\
\hline Valine & 3096 & 193 & 3913 & 447 & 0.07 \\
\hline
\end{tabular}

* Data used were from lactating cows, and were fitted to equation 12 (p. 66).

Hepatic removal of propionate was overpredicted at lower propionate inputs and underpredicted at higher propionate inputs (inputs to the model and predicted uptakes are perfectly correlated). Given that the statistical algorithm utilized attempts to minimize the sums of squares for the error term, prediction residuals ranging from positive to negative as observed for propionate predictions are to be expected. However, if one were to assume that the actual rate parameter $\left(K_{H}\right)$ for removal of propionate was somewhat less than the derived parameter, then the residuals would be distributed such that the model would give satisfactory predictions for propionate removal at low inputs and would underpredict liver removal of propionate at greater inputs of propionate, i.e. a stimulatory factor is required to increase removal at greater propionate concentrations. These results would then apparently be consistent with the relationships among peripheral propionate concentrations, glucagon concentrations, and hepatic propionate removal and subsequent incorporation into glucose, wherein increased peripheral concentrations of propionate stimulate pancreatic production of glucagon which in turn stimulates production of glucose by liver and increased removal of glucose precursors including propionate (Brockman \& Bergman, 1975; Donkin \& Armentano, 1993; Sano et al. 1995). Therefore, one would anticipate that the $K_{H}$ for propionate would increase as concentrations of propionate increased, which is consistent with the observed bias. It is not clear if the observed biases for predictions of hepatic acetate and $\beta$-hydroxybutyrate concentrations were related to those of propionate. However, given that the liver was a net producer of both of these metabolites, it seems more likely that the predictions are biased due to the lack of consideration of hepatic metabolism.
Table 4. Estimates of $K_{M}$ (litres/d) for metabolite uptake by the mammary gland from extracellular space in lactating dairy cows treated with saline or bovine somatotropin (bST)* $\dagger$

(Values are estimates with their standard errors)

\begin{tabular}{|c|c|c|c|c|c|}
\hline & \multicolumn{2}{|c|}{ Saline } & \multicolumn{2}{|c|}{ bST } & \multirow[b]{2}{*}{$P<$} \\
\hline & $K_{M}$ & SE & $K_{M}$ & SE & \\
\hline \multicolumn{6}{|l|}{ Amino acid } \\
\hline Alanine & 1521 & 611 & 1417 & 420 & 0.89 \\
\hline Arginine & 14561 & 1122 & 15824 & 2560 & 0.67 \\
\hline Asparagine & 4243 & 1071 & 4943 & 805 & 0.61 \\
\hline Aspartate & -937 & 693 & 1204 & 317 & 0.007 \\
\hline Cystine & 1298 & 1670 & 189 & 1400 & 0.61 \\
\hline Glutamine & 2460 & 1128 & 3597 & 1298 & 0.52 \\
\hline Glutamate & 10630 & 4125 & 3308 & 872 & 0.03 \\
\hline Glycine & -717 & 638 & 451 & 706 & 0.26 \\
\hline Histidine & 1308 & 551 & 1463 & 472 & 0.83 \\
\hline Isoleucine & 16367 & 1144 & 18069 & 1852 & 0.44 \\
\hline Leucine & 2657 & 476 & 4271 & 623 & 0.05 \\
\hline Lysine & 8425 & 1019 & 8449 & 908 & 0.99 \\
\hline Methionine & 12053 & 2594 & 13355 & 2302 & 0.71 \\
\hline Phenylalanine & 6322 & 633 & 4288 & 718 & 0.05 \\
\hline Proline & 1223 & 619 & 957 & 527 & 0.75 \\
\hline Serine & 5617 & 1041 & 4333 & 868 & 0.36 \\
\hline Threonine & 3908 & 663 & 4183 & 620 & 0.77 \\
\hline Tryptophan & 1099 & 1023 & 1928 & 1340 & 0.62 \\
\hline Tyrosine & 5508 & 606 & 4734 & 548 & 0.36 \\
\hline Valine & 2914 & 419 & 3014 & 430 & 0.87 \\
\hline \multicolumn{6}{|l|}{ Other metabolites } \\
\hline Glucose & 4711 & 289 & 3366 & 497 & 0.03 \\
\hline Acetate & 27528 & 1754 & 27735 & 3051 & 0.96 \\
\hline BHBA & 15805 & 1896 & 8585 & 1510 & 0.06 \\
\hline TAG & 4055 & 1186 & 6345 & 1752 & 0.45 \\
\hline NEFA & 3008 & 483 & 2716 & 757 & 0.75 \\
\hline Glycerol & 13911 & 1515 & 9241 & 2675 & 0.03 \\
\hline Lactate & 139 & 1148 & -36 & 1264 & 0.92 \\
\hline Urea & 232 & 310 & -98 & 242 & 0.54 \\
\hline Citrulline & 1467 & 634 & 2294 & 1318 & 0.52 \\
\hline Ornithine & 7298 & 452 & 6452 & 802 & 0.37 \\
\hline IGF-1 & 4228 & 2039 & -2262 & 2927 & 0.10 \\
\hline
\end{tabular}

BHBA, $\beta$-hydroxybutyrate; TAG, triacylglycerol; NEFA, non-esterified fatty acids; IGF-1, insulin-like growth factor-1.

- Cows treated with bST were injected daily from day 71 to day 128 of lactation. Observations of mammary uptake were made on days 105 and 128 of lactation (Hanigan et al. 1991; Miller ot al. 1991a,b).

† Data were fitted to equation 12. Only whole-blood data were considered.

Biases associated with predictions of citrulline and histidine removal by mammary gland were restricted to whole-blood measurements. It appears that a significant proportion of histidine may be transported in erythrocytes and that this erythrocyte pool is apparently not in equilibrium with the plasma pool (Hanigan et al. 1991; Lobley et al. 1996). Lobley et al. (1996) suggested that erythrocytes may be liberating free histidine from peptides or proteins. If this is the source of the high concentrations of free histidine within the erythrocyte, then one would expect free histidine concentrations to be at least partially dependent on the precursor protein or peptide concentrations which may explain the aforementioned bias. However, the analysis of histidine can be problematic as evidenced by the variation in plasma predictions. Therefore, it is quite possible that the bias associated with wholeblood removal is entirely an artifact of the analyses.

Erythrocytes have also been shown to possess arginase (EC 3.5.3.1) activity (Covolo \& West, 1947). Therefore, it 

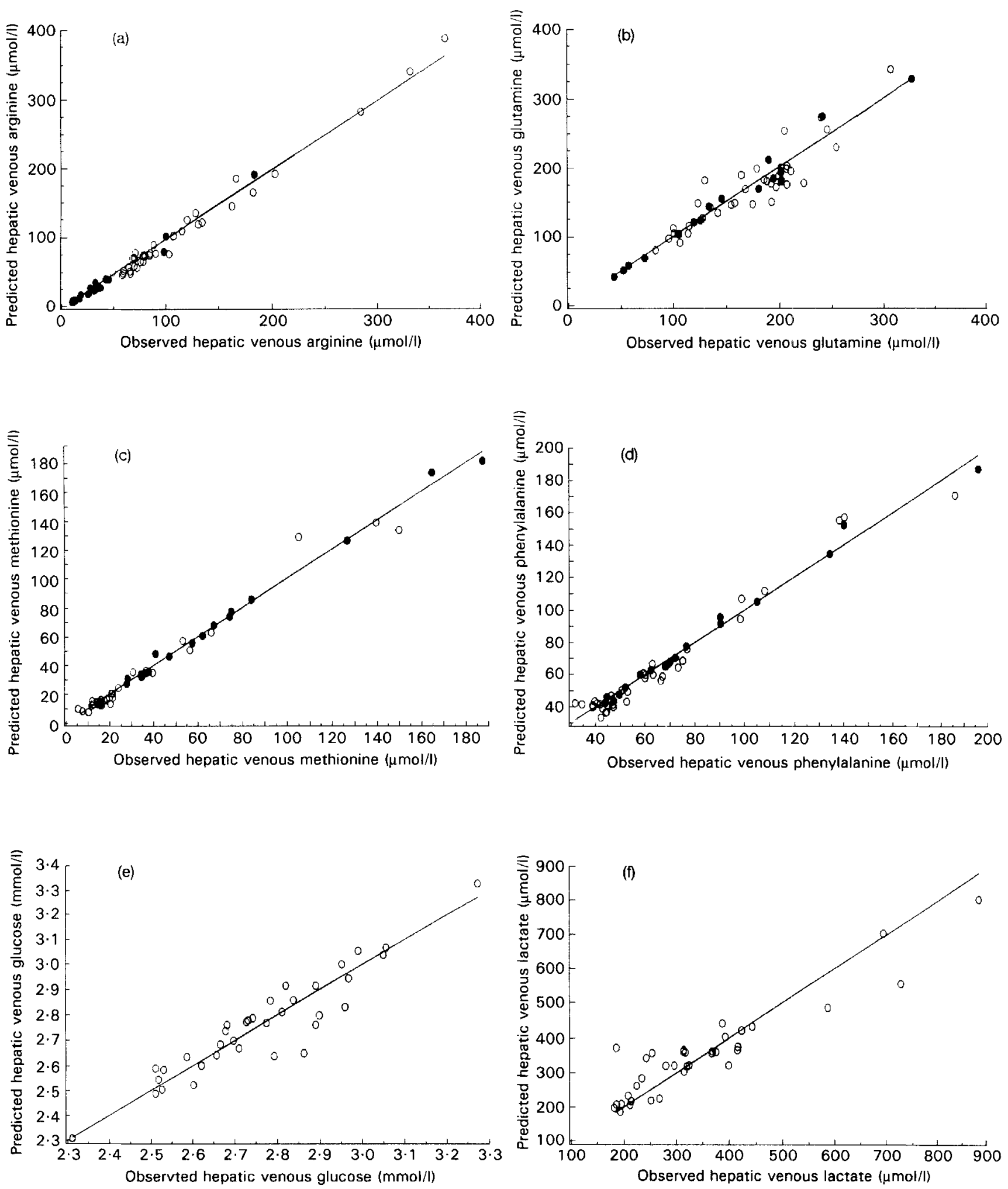

Fig. 3. Observed v. predicted hepatic venous concentrations of (a) arginine, (b) glutamine, (c) methionine, (d) phenylalanine, (e) glucose, and (f) lactate for whole blood $(\Theta)$ and plasma $(O)$. Predictions were generated using equation 6 . Values where observed and predicted values are equivalent are denoted by the line. 

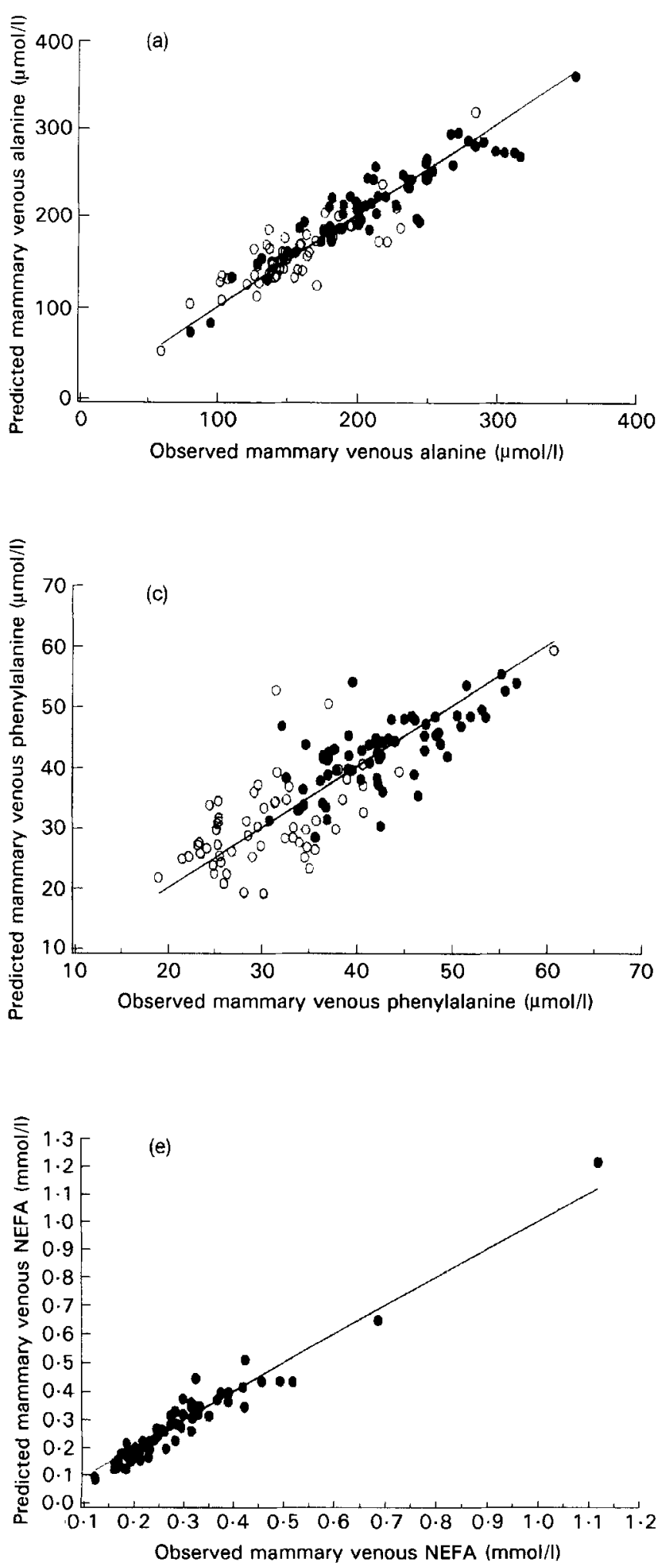
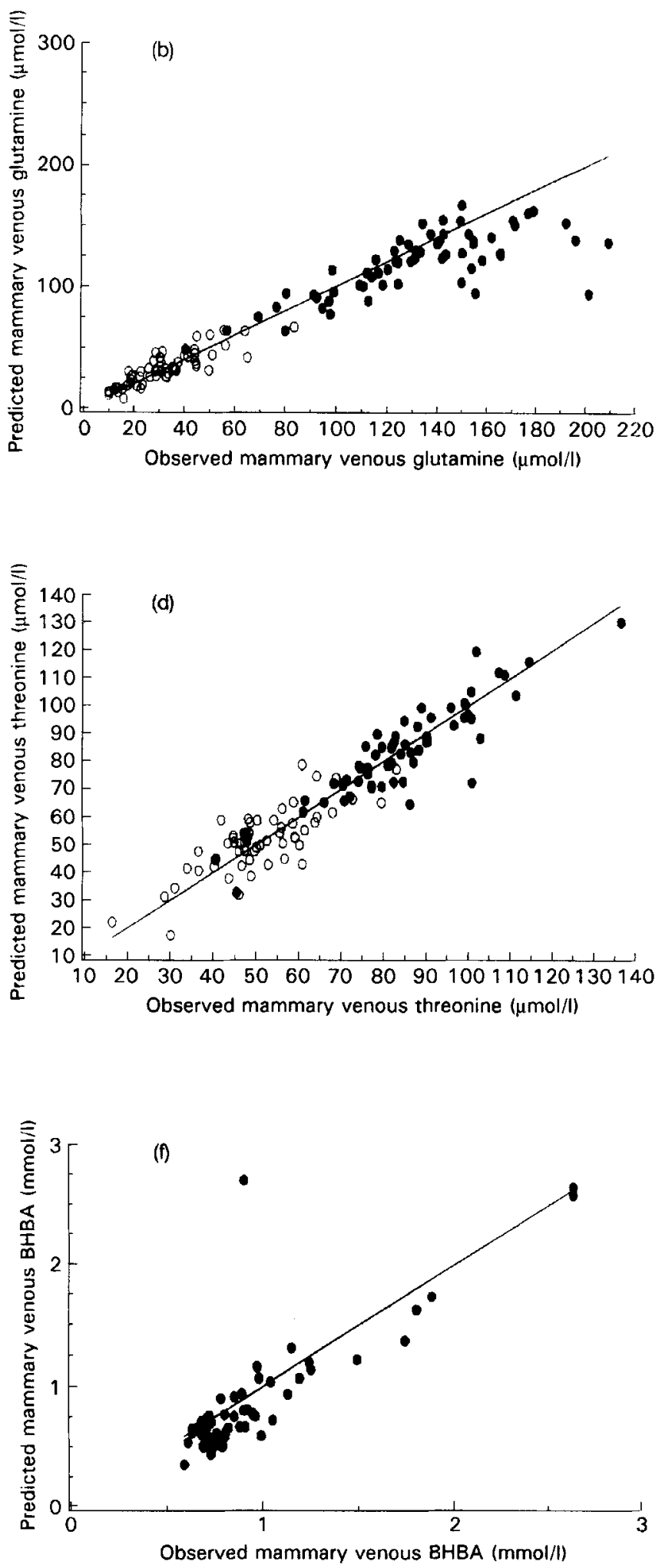

Fig. 4. Observed $v$. predicted mammary venous concentrations of (a) alanine, (b) glutamine, (c) phenylalanine, (d) threonine, (e) non-esterified fatty acids (NEFA), and (f) $\beta$-hydroxybutyrate (BHBA) for whole blood $(\Theta)$ and plasma $(O)$. Predictions were generated using equation 12 . Values where observed and predicted values are equivalent are denoted by the line. 

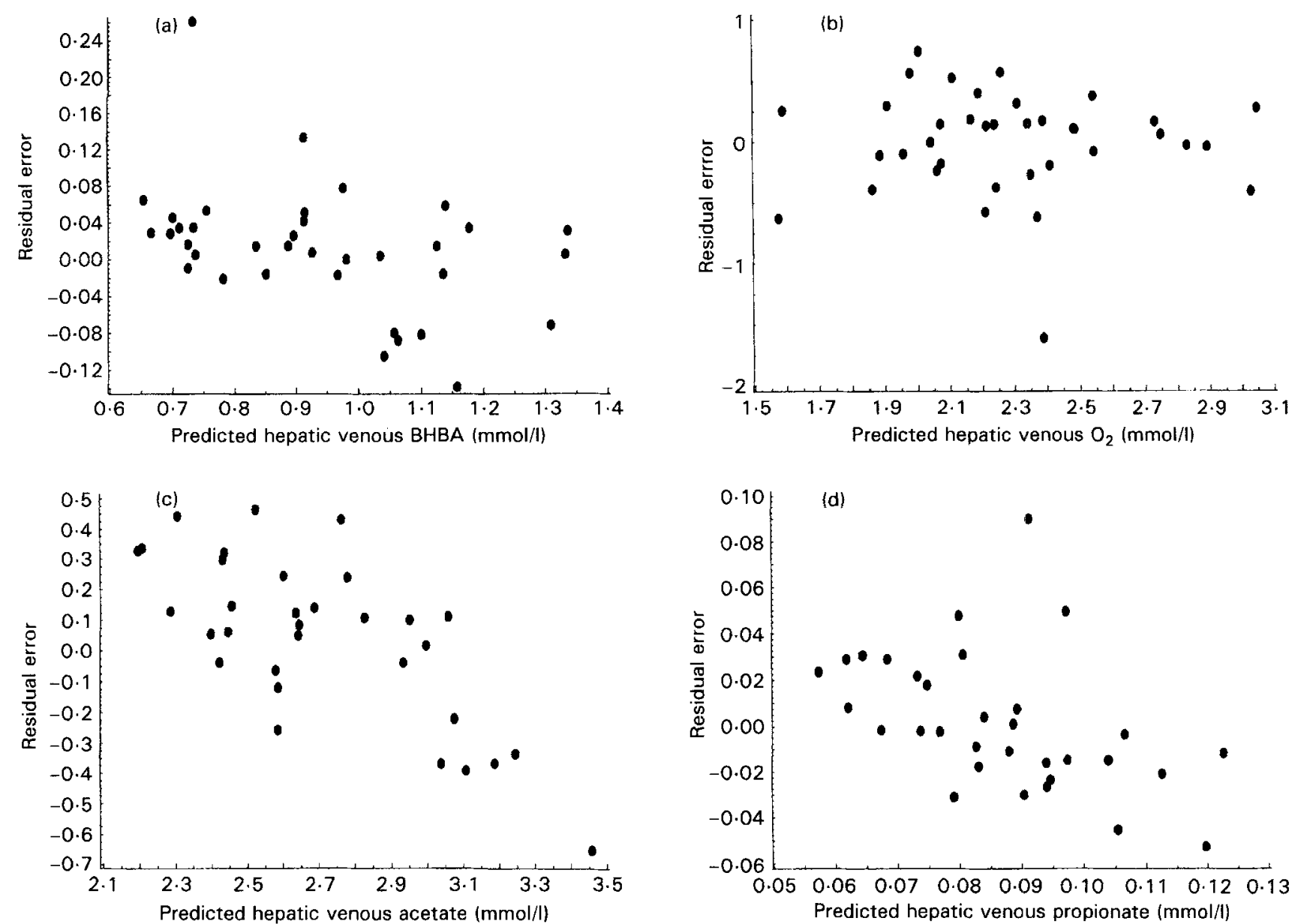

Fig. 5. Residual distributions for predictions of plasma concentrations of hepatic venous (a) $\beta$-hydroxybutyrate (BHBA), (b) $\mathrm{O}_{2},(\mathrm{c})$ acetate, and (d) propionate. Predictions were generated as for Fig. 3. Residuals were calculated as observed - predicted.

seems likely that there would be a net flux of arginine to ornithine and that this flux would be proportional to arginine concentrations. However such a conversion should not result in a bias within the observed arginine concentration ranges as the model cannot discriminate among removal by mammary gland and removal by other sources such as the erythrocyte. The only apparent exception to this is if the conversion of arginine to ornithine is saturable within the observed arginine concentration range. However the lack of any apparent curvilinearity to the residuals for arginine predictions does not support this argument. As such, the data would suggest that some additional regulatory element exists for arginine removal by mammary gland.

It is not clear whether erythrocytes possess ornithine transcarbamoylase ( $E C$ 2.1.3.3) activity, but given that the enzyme is generally associated with mitochondria, it would seem unlikely that the observed bias associated with citrulline removal from whole blood by mammary tissue results from conversion of ornithine or arginine to citrulline within the erythrocyte. It seems more likely that the bias is caused by metabolic events within the mammary gland, although it is not clear why the bias is apparently restricted to whole-blood observations.

The liberation of free glycerol from TAG hydrolysis at the endothelial cell surface would presumably alter the apparent relationship between glycerol input and glycerol removal by mammary tissue. As TAG removal by the mammary gland appeared to exhibit linear kinetics (Table 2 ), the glycerol prediction errors caused by this putative contribution to the free glycerol pool should be associated with arterial TAG concentrations (blood flow is equivalent for both metabolites). Therefore, the prediction errors should be reflected by the correlations among arterial concentrations of glycerol and TAG. As glycerol and TAG concentrations in arterial blood were poorly correlated ( $r^{2} 0.07, P=0.029$ ), one would expect prediction errors for glycerol uptake to be randomly distributed as opposed to the linear bias observed if TAG hydrolysis was the source of error. It is possible that removal of free glycerol is also affected by utilization for milk TAG synthesis. However, since TAG synthesis involves metabolism of a variety of substrates including glucose, acetate, $\beta$-hydroxybutyrate, TAG, non-esterified fatty acids, and glycerol, attempts to 

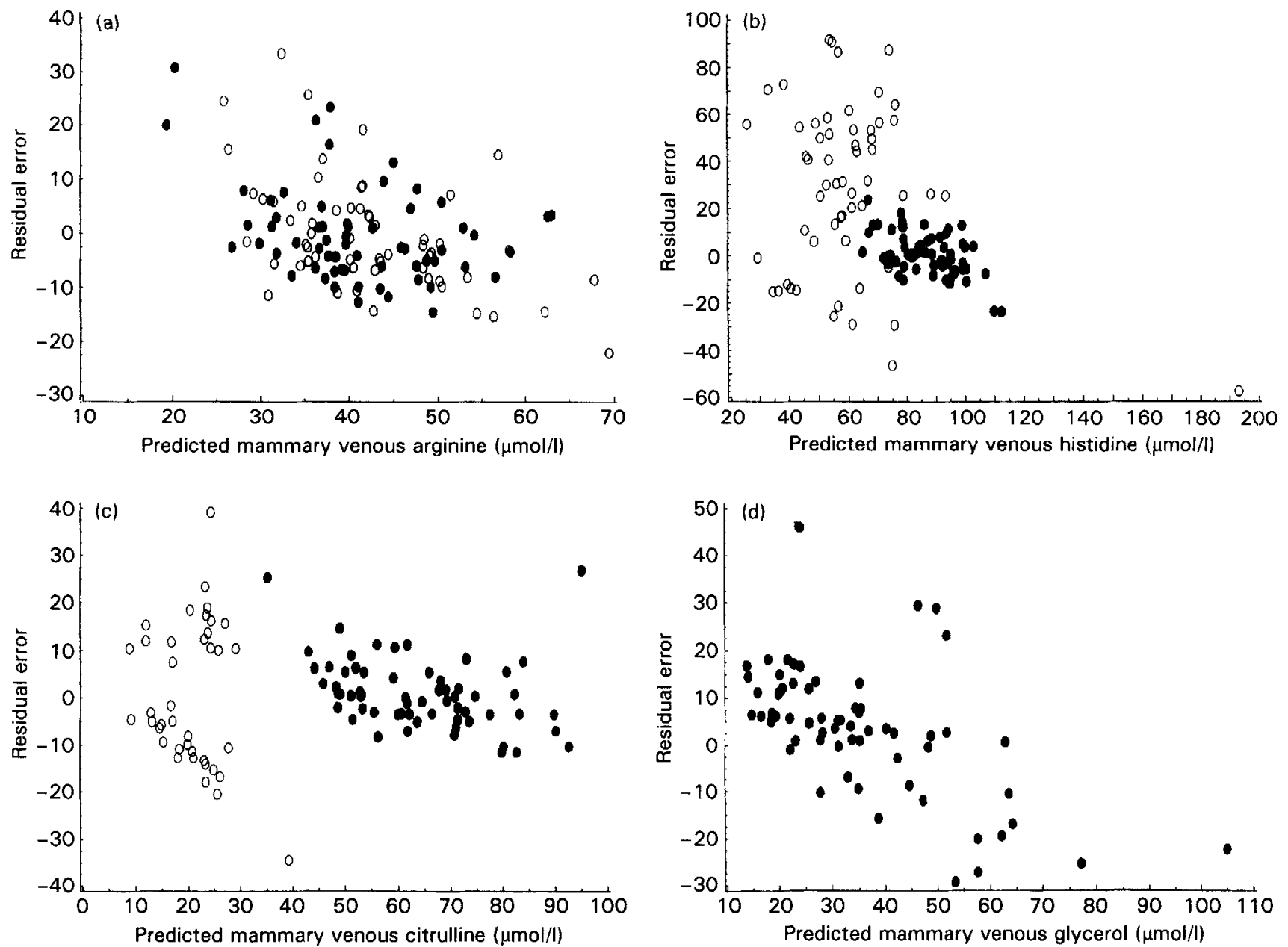

Fig. 6. Residual distrubutions for predictions of mammary venous concentrations of (a) arginine, (b) histidine, (c) citrulline, and (d) glycerol for whole blood $(O)$ and plasma $(O)$. Predictions were generated as for Fig. 4. Residuals were calculated as observed - predicted.

delineate the contribution of glycerol use for TAG synthesis is beyond the scope of the present work.

\section{Predictions with large variance}

Generally, tissues are thought to respond in a local manner to hypoxic conditions by increasing the rate of blood flow to the area. This response has been demonstrated in a number of tissues, although, among these tissues, liver seems to be the least responsive (as reviewed by Detweiler, 1984). Presumably $\mathrm{O}_{2}$ use and thereby removal from blood is driven by substrate oxidation rather than $\mathrm{O}_{2}$ supply. As such, the poor predictability of venous $\mathrm{O}_{2}$ concentrations is not surprising. Similarly, metabolism of $\mathrm{N}$ by liver is very complex and presumably a function of the various precursors and products. Therefore, errors associated with predictions of $\mathrm{NH}_{3}$ removal by liver may very well be associated with changes in intracellular metabolism.

Acetate and glucose metabolism by mammary gland have been observed previously to be related (Forsberg et al. 1984, 1985; Miller et al., 1991a). Such interrelationships were not considered in the present analysis. Use of a more detailed model, such as that described by Hanigan \&
Baldwin (1994), would be required to determine if the majority of the observed bias in acetate predictions was explained by the interrelationship. Alternatively, an integrated model describing only glucose and acetate removal could be derived from equation 12 although no such attempt was made.

\section{Non-significant predictions}

The lack of significance of estimates of $K_{H}$ and $K_{M}$ (positive or negative) for aspartate, isoleucine, leucine, and valine for liver and cystine, glycine, histidine, lactate, urea and IGF-1 for mammary gland suggests a lack of net removal or production of these metabolites by the respective tissues. However, aspartate net removal by liver ranges from positive to negative yielding an overall mean near 0 (results not shown). This range appears to be associated in part with changes in input, i.e. when inputs to the liver were great aspartate removal was positive and when inputs declined aspartate removal was negative. As such, the assumption underlying the derivation of $K_{H}$, i.e. that intracellular efflux was linearly related to extracellular concentrations $\left(K_{H}=k_{E H} V_{E H}-k_{I H} \beta V_{I H}\right)$ appears to be untenable. There- 
fore the subsequent substitution into equation 5 would also be questionable for this particular amino acid. A unique estimation of $k_{E H}$ and $k_{I H}$ requires the use of isotopic data that are not currently available. Attempts to simplify the system whereby $k_{I H} \beta V_{I H}$ was set to a constant greater than 0 were unsuccessful. Presumably this failure was due to the intricacies of $\mathrm{N}$ metabolism in the liver and the effects of such metabolism on aspartate removal by liver. As noted earlier, it is obvious that $\mathrm{N}$ status cannot be predicted in the absence of information on whole liver metabolism.

The technical difficulties associated with cystine analysis may be the primary cause of a non-significant positive estimate of the $K_{M}$ for cystine removal by mammary gland. Furthermore, recent observations suggest that a large proportion of cystine is transported in blood bound to plasma proteins (Lee et al. 1993). As the bound cystine would not be measured, the estimate of $K_{M}$ for cystine would be underestimated by an amount proportional to the udder delivery of bound cystine.

Difficulties in analysing histidine have already been discussed and are probably adequate to explain the apparent lack of histidine removal by mammary gland. Analyses of glycine, lactate, and urea are less problematic. Therefore, estimates of $K_{M}$ near 0 for these metabolites are supportive of previous observations (Cant et al. 1993; Metcalf et al. 1994).

\section{Negative estimates}

Negative estimates of $K_{H}$ for glutamate, glucose, acetate, $\beta$-hydroxybutyrate, and urea indicate that there is a correlation among peripheral concentrations and hepatic production of those metabolites. This seems a plausible explanation as peripheral concentrations of some of these metabolites are largely determined by hepatic output as opposed to other sources such as diet or peripheral tissues. In such cases, circulating concentrations increase as hepatic-vein concentrations increase (indicative of increased hepatic production). Therefore, inputs through portal and arterial supplies are actually a function of hepatic production resulting in a negative correlation between extracellular concentrations and the rate of release by the liver. These observations are supported by observations in pluriparous cows 8 weeks postpartum wherein portal-drained viscera releases of glutamate and glucose were negligible and negative respectively (Reynolds et al. 1988), i.e. the liver was the primary source as opposed to absorption from the diet.

Such a relationship between glucose concentrations and glucose production by liver is somewhat surprising in that production is generally thought to be regulated by glucagon and possibly insulin (Brockman \& Bergman, 1975; Baird et al. 1980; Veenhuizen et al. 1988; Sano et al. 1995). However, if insulin were playing a role in determining the rate of glucose production, one would not expect to see such a strong negative relationship between glucose concentrations and glucose production rate. That is, any effects of insulin on glucose production by liver would be counter to the relationship reported herein and would, thereby, cause a reduction in the correlation coefficient.
Given that glucagon concentrations are not thought to be correlated with circulating glucose concentrations, it could be concluded from this analysis that glucose production by liver is largely substrate-driven.

\section{Parameter estimate patterns}

There were no apparent patterns to $K_{H}$ with respect to essentiality of amino acids, although, branched-chain amino acids were not removed in significant quantities by liver. Surprisingly, some of the largest constants were exhibited for non-essential amino acids such as alanine, asparagine, glutamine, glycine and serine. The liver also appears to exhibit high constants for arginine, methionine, and phenylalanine. The high constant for arginine is consistent with hepatic-renal arginine and citrulline cycling (Bergman et al. 1974). A high $K_{H}$ for phenylalanine removal was surprising in that phenylalanine is thought to be near-limiting for milk protein synthesis on some diets (Hanigan \& Baldwin, 1995). The possibility exists that liver removal of phenylalanine is great in order to ensure a supply of tyrosine via addition of a hydroxyl group to phenylalanine. Such a hypothesis would be consistent with the observed $K_{H}$ for tyrosine being relatively less than the $K_{H}$ for phenylalanine.

As for liver, there were no clear differences in $K_{M}$ for classes of amino acids as defined by Mepham (1982). However, the class I amino acids tended to have greater values for $K_{M}$. A clearer picture is provided by examination of circulating concentrations of metabolites and requirements by the organ. For example, methionine concentrations were extremely low compared with other metabolites, and relative need for milk protein synthesis was moderate yielding a fairly large estimated $K_{M}$. Conversely, concentrations of lysine were roughly fourfold greater than methionine and milk protein needs were roughly threefold greater as compared with methionine, thereby requiring a $K_{M}$ that is less than that for methionine.

The high constant for methionine may simply be a reflection of the low circulating concentrations of methionine. However it is difficult to state whether $K_{M}$ for removal of methionine is great due to low concentrations of circulating methionine or whether circulating concentrations of methionine are chronically low with respect to other amino acids due to high affinities for this amino acid by all tissues.

\section{Treatment effects}

The absence of a bST effect on removal of arginine and lysine is in contrast with previous observations using this data set and an alternative statistical analysis (Hanigan et al. 1992). However, Hanigan et al. (1992) did not consider changes in blood flow when analysing the data. Given the non-linear effects of changes in blood flow, it is possible that the perceived effects of bST on removal of lysine and arginine were due entirely to changes in blood flow.

Although an effect of bST on leucine removal by mammary gland was observed independent of the statistical model chosen, results presented herein indicate an increase 
in leucine $K_{M}$ while previous observations (Hanigan et al. 1992) indicated a reduction in removal. Observed changes in $K_{M}$ for phenylalanine are opposite to those of leucine. As these two amino acids share a common transporter (Baumrucker, 1985), any effects of bST must have been due to changes elsewhere in their metabolic pathways. It cannot be determined from this analysis how these changes were mediated.

The method of analysis presented herein also detected differences in aspartate and glutamate. As for leucine and phenylalanine, it seems unlikely that those changes were mediated by their common transporter (Baumrucker, 1985) due to opposing effects. Rather the changes probably are a result of changes in metabolism particularly since changes in uptake of one could be expected to result in a corresponding change in intracellular concentrations of the other via transamination of tricarboxylic acid cycle intermediates. As intracellular concentrations are the primary determinant of efflux from the cell (equation 7), any changes in metabolism that result in an increase in intracellular concentrations should result in a decline in the apparent $K_{M}$ as indicated by the substitution in equation 11 .

\section{Effects of blood flow and concentration}

Examination of the relationships among metabolite removal, concentrations, and blood flow demonstrate that the kinetic response to greater blood flow is not necessarily similar to the response to metabolite concentrations. Using parameters for methionine (Tables 1 and 2) and equations 6 and 12, it can be seen that increases in metabolite concentrations and blood flows would be predicted to result in linear and non-linear removals for methionine respectively for both organs (Fig. 7). These differences in effects are more pronounced for metabolites with low $K_{H}$ or $K_{M}$. As these rate parameters become greater, the predicted differences in response to flow and concentration become less distinct. For example, changes in propionate removal in response to changes in blood flows or concentrations would be very similar.

Examination of $K_{M}$ and $K_{H}$ for the various metabolites indicates that hepatic removal of essential amino acids could be expected to be largely driven by concentration while mammary removal is driven by both blood flow and concentration. Therefore any increase in blood flow associated with changes in energy intakes (Reynolds, 1995) should have marginal effects on liver thereby preserving essential amino acids for use by the mammary gland. However, changes in systemic concentrations brought about by increased absorption of amino acids would be predicted to result in increased removal of essential amino acids by liver and mammary gland. In such a case, the udder would be predicted to maintain a competitive advantage over liver due to the apparent greater respective $K_{M}$ for the essential amino acids.

Assuming these derived rate parameters are consistent across animals and diets, the observed decrease in blood flow to the mammary gland associated with high-fat diets (Cant et al. 1993) could be expected to have the greatest impact on methionine, arginine, isoleucine, and lysine and
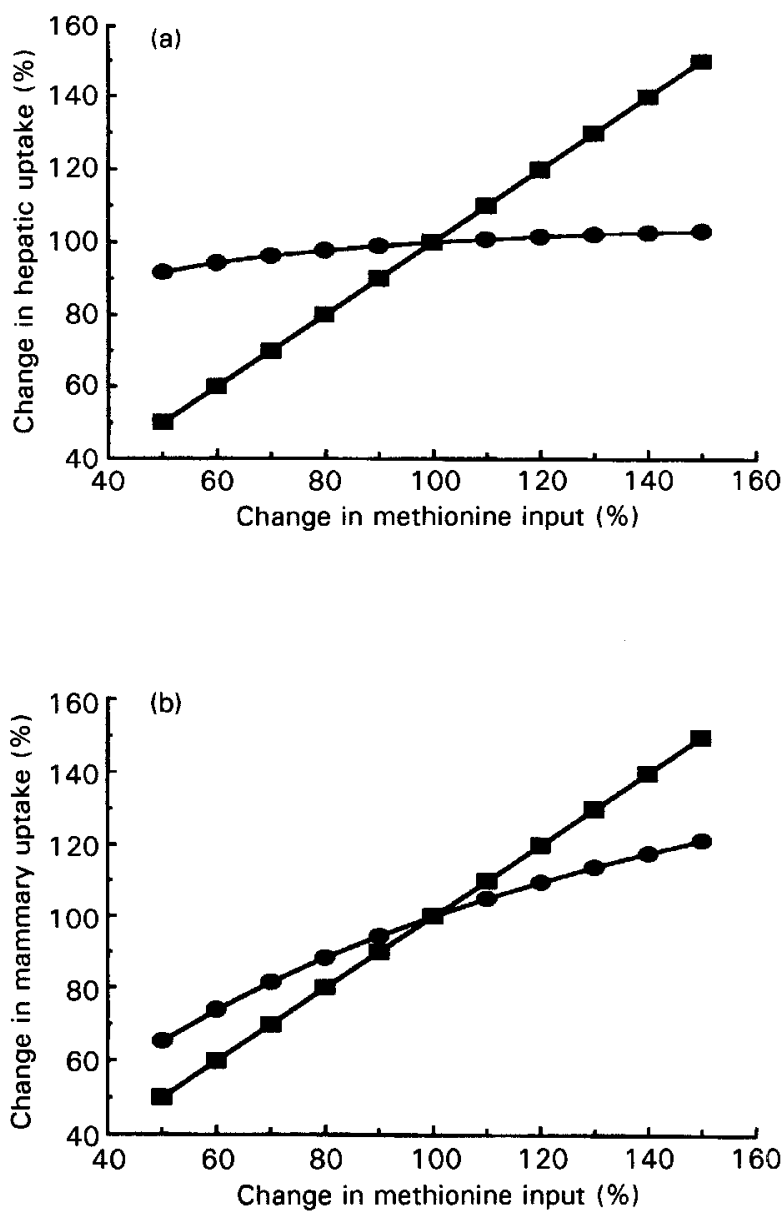

Fig. 7. Effects of changes in blood flow (O) and metabolite concentrations (a) on metabolite removal by (a) liver and (b) mammary gland. $K_{H}$ was assumed to be 4280 litres/d; $K_{M}$ was assumed to be 16113 litres/d; hepatic and mammary blood flows were assumed to be 30 and 10 litres/min repectively at $100 \%$ input; and input concentrations were assumed to be $25 \mu \mathrm{mol} / /$ at $100 \%$ input.

the least impact on threonine, valine, leucine, and tryptophan removal. Changes in blood flow would also have great impact on mammary removal of acetate, TAG, and $\beta$-hydroxybuyrate.

The liver may have an advantage in removal of propionate, butyrate and $\mathrm{NH}_{3}$ as evidenced by large $K_{H}$ values for these metabolites. However, a direct comparison cannot be made due to the lack of observations for these metabolites for mammary gland. Given these high rate constants, removal of these metabolites by liver should also be responsive to changes in blood flow which would serve to link intake and removal, i.e. as portal appearance increases, hepatic removal will increase. Such a system would apparently allow the liver to respond to increased blood flows associated with greater energy intakes (Reynolds, 1995) by removing greater quantities of propionate without removing significantly greater quantities of essential amino acids. The liver also appears to have an advantage in the removal of alanine and glycine. 
Using the model for liver, associated parameters, and a given set of representative input conditions, one can easily calculate a fractional extraction for a single pass through the liver where fractional extraction refers to the fractional proportion of input that is removed by liver (an alternative approach used that should not be confused with that used herein is to express removal during the treatment period as a fractional proportion of the input observed during the control period). For example, the fractional extraction of methionine would be $8 \%$ with respect to input (using the rate constant from Table 1) when arterial and portal methionine concentrations are 25 and $32 \mu \mathrm{mol} / 1$, respectively and hepatic arterial and portal vein blood flows are 6.8 and 27 litres/min respectively (Reynolds et al. 1988). If portal concentrations increase by $10 \mu \mathrm{mol} / \mathrm{l}$ with no associated changes in the other parameters, the input of methionine to the liver would increase by approximately $25 \%$ but the fractional extraction would remain at $8 \%$. However, if blood flow increased by $25 \%$ (split appropriately between arterial and portal flows), input of methionine would again increase by $25 \%$ but the fractional extraction rate would decline to $6.6 \%$ which corresponds to a minor increase in net removal. Therefore, the expression of transorgan data as fractional extractions and the subsequent interpretation of these extractions would appear to be of questionable value and may lead one to misinterpret the data particularly if large changes in blood flow are associated with treatments. Additionally, the prediction of removal by an organ based on arterial and portal concentrations, blood flow, and a presumed extraction coefficient may result in large errors. The latter approach has rarely been applied to splanchnic experiments but has been used routinely for mammary experiments.

Following on from the given example, an increase in the rate of portal appearance of a given metabolite will result in greater rates of delivery to the liver. Assuming no change in blood flow, the liver will respond by removing a fraction of the increase as discussed earlier. This metabolite then becomes available for use by peripheral tissues. However, since hepatic blood flows are so great, a large proportion of this increase will be recycled through the splanchnic tissues. This recycling results in an increase in arterial concentrations and subsequently in portal concentrations (assuming minimal changes in ruminal and hind-gut use). The liver is then presented with metabolite concentrations that are elevated to a greater extent than the fractional increase provided by gut absorption. Since the fractional extraction by liver is constant with respect to concentration changes (see earlier), the net removal per unit of time will increase as arterial concentrations increase. Additionally, if a metabolite is not removed by peripheral tissues, arterial concentrations will increase further, resulting in even greater rates of hepatic removal per unit of time. This physical link among tissues allows the coordination of portal appearance of metabolite, peripheral use, and hepatic removal even in the absence of changes in endocrine status. Although such a system of hepatic 'regulation' greatly simplifies any efforts to build a more integrative model of postabsorptive amino acid metabolism, the description of such does not offer any direct insight as to how to reduce hepatic catabolism of amino acids other than to increase peripheral usage.

Of course, for some metabolites, manipulation of hepatic function may be necessary to meet the needs of the system. For example, propionate is required by liver to maintain adequate rates of glucose synthesis. Other tissues such as mammary gland may have high affinities for propionate but do not require it. Therefore, it seems logical that liver utilization might be influenced by other factors such as glucagon status in order to assure an adequate rate of glucose synthesis. It should also be noted that the experiments utilized for these analyses were not designed to examine all the possible effects of hormones on tissue metabolite removal. Additionally, both experiments were designed such that diets fed were isoenergetic. Therefore, the potential effects of energy status on mammary and liver metabolite removal were not examined. If energy status of the liver plays a role in, for example, lysine removal by liver, then the simple model of hepatic lysine removal presented herein would need to be modified. Of course, such an effect could be determined by application of this model in a manner similar to the analysis presented in Tables 3 and 4 to the appropriate experimental observations.

One point worth noting is that for metabolites with relatively low hepatic extractions, one could not expect to discriminate the relative impact of hepatic removal on peripheral usage through the use of jugular $v$. portal or mesenteric vein infusions of substrates, respectively, i.e. the differences among portal, mesenteric, and jugular infusions in terms of peripheral availability would be sufficiently small as to be difficult to detect given the normal error of measurement.

Cant \& McBride (1995) also considered the effects of blood flow in their model of mammary blood flow. However, that work was conducted to explore some of the principles of capillary diffusion and thus that model is considerably more complex than the present work. Although the derivation and expression of the model presented herein is different from that of Cant \& McBride (1995) the underlying principles are similar and thus the response to increasing blood flow is identical. Therefore, this work is consistent with that of Cant \& McBride (1995).

While the simple approach undertaken here appears to work for this data set, the data were largely derived from animals consuming a diet with a constant energy density. If simulation of experimental observations is the desired endpoint as opposed to a description of the system as presented here, a more robust approach including hormonal regulation would probably be required to accommodate hepatic and mammary performance across a wider range of dietary energy levels. A more integrated model could be expected to predict $\mathrm{CO}_{2}$, urea, aspartate, glutamate, $\mathrm{NH}_{3}$, and glucose metabolism based on inputs to the model as opposed to simply relating them to circulating concentrations. However, this simple model can still be utilized to evaluate changes in removal of metabolites in association with various treatments. It can also serve as a submodel for more integrative models of tissue metabolism (Hanigan \& 
Baldwin, 1994) wherein predictions of metabolite removal serve as inputs to the various metabolic pathways described in the model.

\section{Acknowledgements}

The constructive comments provided by Dr Ray Boston on the statistical analyses were greatly appreciated. This work was supported as part of a consortium of government and industrial entities including the Ministry of Agriculture, Fisheries and Food, the Biotechnology and Biological Science Research Council, Purina Mills, Inc., the Milk Development Council of England and Wales, and NUTRECO, Inc.

\section{References}

Baird GD, Lomax MA, Symonds HW \& Shaw SR (1980) Net hepatic and splanchnic metabolism of lactate, pyruvate and propionate in dairy cows in vivo in relation to lactation and nutrient supply. Biochemical Journal 186, 47-57.

Bass R, Hedegaard HB, Dillehay L, Moffett J \& Englesberg E (1981) The A, ASC, and L systems for the transport of amino acids in Chinese Hamster Ovary Cells (CHO-K1). Journal of Biological Chemistry 256, 10259-10266.

Baumrucker CR (1985) Amino acid transport systems in bovine mammary tissue. Journal of Dairy Science 68, 2436-2451.

Bergman EN, Kaufman CF, Wolff JE \& Williams HH (1974) Renal metabolism of amino acids and ammonia in fed and fasted pregnant sheep. American Journal of Physiology 226, 833-837.

Brockman RP \& Bergman EN (1975) Effect of glucagon on plasma alanine and glutamine metabolism and hepatic gluconeogenesis in sheep. American Journal of Physiology 28, 16271633.

Cant JP, DePeters EJ \& Baldwin RL (1993) Mammary amino acid utilization in dairy cows fed fat and its relationship to milk protein depression. Journal of Dairy Science 76, 762-774.

Cant JP \& McBride BW (1995) Mathematical analysis of the relationship between blood flow and uptake of nutrients in the mammary glands of a lactating cow. Journal of Dairy Research 62, 405-422.

Christensen HN, Liang M \& Archer EG (1967) A distinct $\mathrm{Na}^{+}-$ requiring transport system for alanine, serine, cysteine, and similar amino acids. Journal of Biological Chemistry 242, 5237-5246.

Clark RM, Chandler PT, Park CS \& Norman AW (1980) Extracellular amino acid effects on milk protein synthesis and intracellular amino acid pools with bovine mammary cells in culture. Journal of Dairy Science 63, 1230-1234.

Covolo GC \& West R (1947) The activity of arginase in red blood cells. Journal of Clinical Endocrinology 7, 325-330.

Detweiler DK (1984) Control mechanisms of the circulatory system. In Dukes' Physiology of Domestic Animals, 10th ed., pp. 163-191 [J Swenson, editor]. Ithaca, NY: Comstock Publishing Assoc.

Donkin, SS \& Armentano LE (1993) Preparation of extended in vitro cultures of bovine hepatocytes that are hormonally responsive. Journal of Animal Science 71, 2218-2227.

Forsberg NE, Baldwin RL \& Smith NE (1984) Roles of acetate and its interactions with glucose and lactate in cow mammary tissue. Journal of Dairy Science 67, 2247-2254.

Forsberg NE, Baldwin RL \& Smith NE (1985) Roles of glucose and its interactions with acetate in maintenance and biosynthesis in bovine mammary tissue. Journal of Dairy Science 68, 2544-2549.
Hanigan MD \& Baldwin RL (1994) A mechanistic model of mammary gland metabolism in the lactating cow. Agricultural Systems 45, 369-419.

Hanigan MD \& Baldwin RL (1995) Dynamic models of ruminant mammary metabolism. In Modeling Ruminant Digestion and Metabolism, pp. 370-412 [RL Baldwin, editor]. New York: Chapman \& Hall.

Hanigan MD, Calvert CC, DePeters EJ, Reis BL \& Baldwin RL (1991) Whole blood and plasma amino acid uptakes by lactating bovine mammary glands. Journal of Dairy Science 74, 2484-2490.

Hanigan MD, Calvert CC, DePeters EJ, Reis BL \& Baldwin RL (1992) Kinetics of amino acid extraction by lactating mammary glands in control and sometribove-treated Holstein cows. Journal of Dairy Science 75, 161-173.

Heitmann RN \& Bergman EN (1980) Transport of amino acids in whole blood and plasma of sheep. American Journal of Physiology 239, E242-E247.

Huntington GB (1984) Net absorption of glucose and nitrogenous compounds by lactating Holstein cows. Journal of Dairy Science, 67, 1919-1927.

Lee J, Harris PM, Sinclair BR \& Treloar BP (1993) Whole body metabolism of cysteine and glutathione and their utilization in the skin of Romney sheep: consequences for wool growth. Journal of Agricultural Science, Cambridge 121, 111-124.

Lobley GE, Connell A, Revell DK, Bequette BJ, Brown DS \& Calder AG (1996) Splanchnic bed transfers of amino acids in sheep blood and plasma, as monitored through the use of a multiple $\left[\mathrm{U}-{ }^{13} \mathrm{C}\right]$ amino acid mixture. British Journal of Nutrition 75, 217-235.

Matsumoto M, Kurohmaru M, Hayashi Y, Nishinakagawa H \& Otsuka J (1994) Permeability of mammary gland capillaries to ferritin in mice. Journal of Veterinary Medical Science 56, 65-70.

Mepham TB (1982) Amino acid utilization by lactating mammary gland. Journal of Dairy Science 65, 287-298.

Metcalf JA, Beever DE, Sutton JD, Wray-Cahen D, Evans RT, Humphries DJ, Backwell FRC, Bequette BJ \& MacRae J (1994) The effect of supplementary protein on in vivo metabolism of the mammary gland in lactating dairy cows. Joumal of Dairy Science 77, 1816-1827.

Miller PS, Reis BL, Calvert CC, DePeters EJ \& Baldwin RL (1991a) Patterns of nutrient uptake by the mammary glands of lactating dairy cows. Journal of Dairy Science 74, 3791-3799.

Miller PS, Reis BL, Calvert CC, DePeters EJ \& Baldwin RL (1991b) Relationship of early lactation and bovine somatotropin on nutrient uptake by cow mammary glands. Journal of Dairy Science 74, 3800-3806.

Oxender DL \& Christensen HN (1963) Distinct mediating systems for the transport of neutral amino acids by the Ehrlich cell. Journal of Biological Chemistry 238, 3686.

Reynolds CK (1995) Quantitative aspects of liver metabolism in ruminants. In Ruminant Physiology: Digestion, Metabolism, Growth, and Reproduction. Proceedings of the 8th International Symposium of Ruminant Physiology, pp. 351-371 [W Engelhardt, S Leonhard-Marek, G Breves and D Giesecke, editors]. Stuttgart: Ferdinand Enke Verlag.

Reynolds CK, Huntington GB, Tyrrell HFJ \& Reynolds PJ (1988) Net portal-drained visceral and hepatic metabolism of glucose, L-lactate, and nitrogenous compounds in lactating Holstein cows. Journal of Dairy Science 71, 1803-1812.

Risau W (1995) Differentiation of endothelium. FASEB Journal 9. 926-933.

Roughton FJW (1964) Transport of oxygen and carbon dioxide in blood. In Handbook of Physiology. Section 3: Respiration, vol. 1, pp. 767-825 [WO Fenn and H Rahn, editors]. Washington, DC: American Physiology Society. 
Sano H, Hayakawa S, Takahashi H \& Terashima Y (1995) Plasma insulin and glucagon responses to propionate infusion into femoral and mesenteric veins in sheep. Journal of Animal Science, 73, 191-197.

Statistical Analysis Systems (1988) SAS/STAT ${ }^{(\mathbb{A})}$ User's Guide, Release 6.03 ed. Cary, NC: SAS Institute, Inc.

Veenhuizen JJ, Russell RW \& Young JW (1988) Kinetics of metabolism of glucose, propionate and $\mathrm{CO}_{2}$ in steers as affected by injecting phlorizin and feeding propionate. Journal of Nutrition 118, 1366-1375.
Waghorn GC (1982) Modelling analyses of bovine mammary and liver metabolism. PhD Thesis, University of California, Davis. Waghorn GC \& Baldwin RL (1984) Model of metabolite flux within mammary gland of the lactating cow. Journal of Dairy Science 67, 531-544.

Wray-Cahen D, Roberts S, Metcalf JA, Backwell FRC, Bequette BJ, Brown DS \& Lobley GE (1997) Hepatic response to increased exogenous supply of amino acids by infusion into the hepatic portal vein of Holstein-Friesian cows in late gestation. British Journal of Nutrition 78, 913-930. 